\title{
JURISPRUDENCIA GENERAL: DERECHO ADMINISTRATIVO (SEGUNDO SEMESTRE 2016)
}

\author{
Aitana DE LA VARGA PASTOR \\ Profesora lectora, acreditada por ANECA a contratada doctora \\ Universitat Rovira $i$ Virgili
}

En el período que nos concierne, en esta ocasión de abril a octubre de 2016, las salas de lo Contencioso-Administrativo del Tribunal Supremo han resuelto, una vez más, numerosos recursos en los que el objeto está relacionado directa o indirectamente con el derecho ambiental y, en definitiva, con el medio ambiente. De todas las sentencias vamos a destacar, como de costumbre, aquellas que nos han parecido más relevantes y nos detendremos en aquellos aspectos que consideramos más importantes. Son de nuevo destacables las sentencias relacionadas con la evaluación ambiental estratégica (EAE) y también las que tienen como objeto los espacios naturales y las actividades extractivas, la protección del paisaje, el desarrollo urbanístico sostenible, los residuos o el comercio de derechos de emisión. Especial mención merecen las numerosas sentencias que tratan sobre derecho de la energía, en concreto las energías renovables.

En relación con la evaluación ambiental, a continuación abordamos de forma cronológica distintas sentencias que nos han parecido destacables.

En primer lugar, la STS de 25 de abril de 2016 (ponente: Eduardo Calvo Rojas) ${ }^{1}$ resuelve el recurso contencioso-administrativo interpuesto contra un permiso de investigación de hidrocarburos por un período de seis años. La asociación recurrente pide la nulidad de pleno derecho del Real Decreto que lo otorga alegando tres motivos. En primer lugar, considera que no incorpora las medidas de protección ni el plan de restauración que requiere la Ley del Sector de Hidrocarburos. En segundo lugar, alega la falta de evaluación ambiental. Este motivo es desestimado. El Tribunal entiende que se trata de un "proyecto" singular de actividad industrial referido a una determinada actividad exploratoria, y no un plan o programa. Asimismo, considera que no está sujeto a una

\footnotetext{
${ }^{1}$ ROJ: STS 1748/2016 - ECLI:ES:TS:2016:1748.
} 
declaración de impacto ambiental conforme a la norma entonces aplicable, el Real Decreto Legislativo 1/2008. El tercer motivo también es desestimado. A pesar de la desestimación del recurso, es interesante destacar la cuestión relacionada con la evaluación ambiental, ya que realiza aclaraciones en relación con la cuestión compleja del ámbito de aplicación de la evaluación de impacto ambiental y de la evaluación ambiental estratégica al considerar que este tipo de proyectos, en aplicación de aquella normativa hoy derogada, están excluidos.

También en relación con la evaluación de impacto ambiental de proyectos, cabe mencionar la STS de 10 de mayo de 2016 (ponente: Eduardo Espín Templado) ${ }^{2}$, que resuelve un recurso de casación contra la aprobación de un proyecto de modificación de carretera.

En tercer lugar, es oportuno citar la STS de 26 de julio de 2016 (ponente: Rafael Fernández Valverde) ${ }^{3}$, que resuelve un recurso de casación relacionado con la aprobación, mediante Resolución de 30 de abril de 2009 de la Subsecretaría del Ministerio de la Presidencia — publicada en el BOE de 8 de mayo de 2009—, del estudio estratégico ambiental del litoral español para la instalación de parques eólicos marinos. La sentencia que resolvió el recurso contencioso-administrativo lo estimó en parte y consideró que "el Estudio Ambiental no puede incluir aguas interiores, pues el Real Decreto 1028/2007, de 20 de julio, por el que se establece el procedimiento administrativo para la tramitación de las solicitudes de autorización de instalaciones de generación eléctrica en el mar territorial, sólo proyecta su eficacia sobre dicho ámbito territorial, excluyendo, para el caso concreto, del Estudio las aguas interiores y que pueda haber una zonificación para la implantación de estos parques eólicos" (FJ 2. ${ }^{\circ}$ ). El TS, sin embargo, considera que no se está ante un conflicto competencial, sino ante la necesidad de delimitar territorialmente qué se considera mar territorial y qué aguas interiores. Destacamos el siguiente párrafo:

Dicho de otra forma, como quiera que la Xunta de Galicia cuenta con competencias en el ámbito de su aguas territoriales, tiene, por ello, legitimación para la impugnación del Estudio Estratégico aprobado por el Estado, que, con la aprobación del citado Estudio $-\mathrm{y}$ al incluir en su ámbito las aguas interiores gallegas-, ha

\footnotetext{
${ }^{2}$ ROJ: STS 2110/2016 - ECLI:ES:TS: 2006:2110.

${ }^{3}$ ROJ: STS 3795/2016 - ECLI: ES: TS: 2016:3795.
} 
invadido el "ámbito territorial gallego", aunque no las competencias de la Xunta, de las que carece en la materia [FJ 5. ${ }^{\circ}$.

En cuarto lugar, cabe destacar también la STS de 18 de octubre de 2016 (ponente: Eduardo Espín Templado) ${ }^{4}$, que resuelve un recurso de casación contra la Sentencia dictada por la Sala de lo Contencioso-Administrativo (Sección 8.a) de la Audiencia Nacional el 11 de noviembre de 2013, por la que se estimaba en parte el recurso contencioso-administrativo interpuesto por el Centro de Ocio Marín-Morrazo, S. L., contra la Orden FOM/1597/2010, de 4 de junio, por la que se aprueba la modificación del Plan de utilización de los espacios portuarios del puerto de Marín y ría de Pontevedra, la cual fue anulada. En este recurso se alegan cuatro motivos de casación, que son desestimados. La cuestión fundamental que se plantea en este litigo y que debe dilucidar el Tribunal Supremo es si la modificación de un plan de utilización de espacios portuarios debe someterse o no a evaluación ambiental o, en otros términos, si el Plan en sí requiere evaluación ambiental o solo deben ser evaluadas las actuaciones contempladas en él. El Tribunal Supremo considera que sí resulta exigible la evaluación ambiental estratégica para la modificación del Plan de usos de los espacios portuarios. Esta sentencia es interesante para delimitar de nuevo el ámbito de aplicación de la evaluación ambiental estratégica. Además, y ello debe ser destacado, frente al razonamiento seguido por el abogado del Estado en el litigio que dio lugar a la sentencia objeto de análisis, considera que la ausencia de una evaluación ambiental legalmente preceptiva del Plan no puede quedar subsanada por la evaluación posterior de las concretas actuaciones contempladas en dicho plan o programa. Destacamos el siguiente fragmento:

[...] Dicha tesis resulta inaceptable, pues supondría admitir la no preceptividad de la obligación de evaluación ambiental de planes y programas, en realidad de la Ley 9/2006. Como es evidente, la obligación de someter a evaluación ambiental tales planes y programas tiene precisamente el objetivo de hacer una previsión ambiental sistemática a más largo plazo, evitando el riesgo de que una evaluación específica de actuaciones concretas en un determinado ámbito territorial no permita ver el efecto acumulativo de las mismas y su incidencia ambiental conjunta. La evaluación ambiental de planes y programas, contemplada en diversos instrumentos internacionales mencionados en la exposición de motivos de la Ley 9/2006, y la Directiva 2001/42/CE, del Parlamento Europeo y del Consejo, relativa a la

\footnotetext{
${ }^{4}$ STS 4471/2016 - ECLI:ES:TS:2016:4471.
} 
evaluación de los efectos de determinados planes y programas en el medio ambiente, justifican la aprobación de la citada Ley 9/2006 (trasposición de la citada Directiva), cuya eficacia quedaría invalidada en gran medida si se admitiese que la falta de realización de una evaluación legalmente preceptiva de un plan o programa quedase subsanada por la evaluación posterior de las concretas actuaciones contempladas en dicho plan o programa [FJ 2. ${ }^{\circ}$.

A continuación abordamos varias sentencias relacionadas con la evaluación ambiental y los espacios naturales. En relación con esta cuestión, encontramos varias sentencias destacables. En primer lugar, la STS de 29 de junio de 2016 (ponente: Mariano de OroPulido López) $)^{5}$. Esta sentencia también está relacionada directamente con el urbanismo, pues trata sobre la legalidad de la aprobación de un plan parcial urbanístico y la exigencia de someterlo a evaluación ambiental estratégica. En esta ocasión se plantea la conveniencia de someterlo a EAE puesto que afecta a una zona colindante con un espacio natural protegido, un LIC declarado ZEC por el Decreto 105/2014. La pretensión no prospera, ya que el plan de gestión del ZEC somete a evaluación los planes y programas correspondientes. Además, el POUM del que se deriva, fue aprobado con anterioridad al 21 de julio de 2004, fecha a partir de la cual es exigible la aplicación de la Ley 6/2009, de 28 de abril, de Evaluación Ambiental de Planes y Programas, hoy derogada por la Ley 21/2013, de 9 de diciembre, de Evaluación Ambiental, y que alega el ayuntamiento recurrente. El interés reside en el debate sobre el alcance de la exigibilidad de EAE a los planes y programas, a cuáles y desde cuándo.

En segundo lugar, encontramos la STS de 11 de julio de 2016 (ponente: Rafael Fernández Valverde $)^{6}$, donde se dirime sobre la construcción de una carretera cuyo proyecto afecta a la ZEPA y LIC de Montes de Toledo e incide negativamente en la fauna y la flora en ella protegidos. Esta sentencia es una muestra de la intervención del Alto Tribunal en una decisión discrecional como la construcción de una carretera y de su control jurisdiccional, y en ella se priman los intereses ambientales frente a otros. Destacamos el siguiente fragmento de la Sentencia:

No podemos considerar, pues, que la sentencia impugnada haya infringido los preceptos - comunitarios y estatales - así como la jurisprudencia citados como infringidos. De la mencionada valoración probatoria podemos deducir que el

\footnotetext{
${ }^{5}$ ROJ: STS 3050/2016 - ECLI: ES: TS: 2016:3050.

${ }^{6}$ ROJ: STS 3272/2016 - ECLI: ES: TS: 2016:3272.
} 
proyecto vial cuestionado se ubica en un lugar caracterizado por contar con un tipo de hábitat natural y/o unas especies prioritarios; pues bien, desde esta perspectiva la Sala de instancia ha considerado infringido el citado precepto 6.4, en su párrafo segundo, por cuanto para tal supuesto fáctico se impone un condicionamiento mucho más intenso; en concreto, se añade y dispone: "únicamente se podrán alegar — como motivos para la aprobación del proyecto- - consideraciones relacionadas con la salud humana y la seguridad pública, o relativas a consecuencias positivas de primordial importancia para el medio ambiente, o bien, otras razones imperiosas de interés público de primer orden".

Limitándonos a éste último aspecto, evidente resulta que las "razones imperiosas de interés público de primer orden" exigidas no podemos percibirlas en las resoluciones que se impugnan. Es cierto que en el mismo se hace referencia a una serie de razones relacionadas con la mejora de la comunicación vial entre dos importantes ciudades de Castilla La Mancha, como son Toledo y Ciudad Real. La jurisprudencia comunitaria, obviamente - mediante medidas compensatorias - permite, por las imperiosas razones expresadas de interés público, proceder a la autorización, pero las mismas deben contar con tal exclusivo carácter y deben quedar suficientemente explicitadas.

Así lo reconoció, entre otras, la STUE de 16 de julio de 1996 [...] [FJ 2. ${ }^{\circ}$.

Veamos ahora aquellas sentencias que tratan sobre espacios naturales. En primer lugar, en la STS de 27 de septiembre de 2016 (ponente: Rafael Toledano Cantero) ${ }^{7}$ se resuelve un recurso de casación presentado por una empresa de actividades extractivas contra la sentencia que resuelve el recurso contencioso-administrativo que desestima su pretensión. Esta empresa de extracción de áridos entiende que tiene derecho a una indemnización por responsabilidad patrimonial de la Administración al proteger el espacio en el que desarrollaba su actividad; sin embargo, el Alto Tribunal considera lo contrario.

La cuestión fundamental a dilucidar por el Tribunal Supremo es si existe o no responsabilidad patrimonial del legislador por los perjuicios derivados de la aplicación de la Ley 6/1994, de 28 de junio, sobre el Parque Regional en torno a los ejes de los cursos bajos de los ríos Manzanares y Jarama, y, en consecuencia, si procede o no indemnización por el daño económico producido a la entidad recurrente, dada la imposibilidad de

\footnotetext{
${ }^{7}$ STS 4347/2016 - ECLI:ES:TS:2016:4347.
} 
explotar recursos mineros de la sección A) en los terrenos afectados por las limitaciones del Parque Regional del Suroeste como consecuencia de la citada Ley y sus instrumentos de desarrollo (Decreto 27/1999, de 11 de febrero, del Consejo de Gobierno de la Comunidad de Madrid, por el que se aprueba el Plan de Ordenación de los Recursos Naturales del Parque Regional en torno a los ejes de los cursos bajos de los ríos Manzanares y Jarama, y Decreto 9/2009, de 5 de febrero, por el que se aprueba el Plan Rector de Uso y Gestión de dicho parque).

El Tribunal Supremo considera que la prohibición introducida por la Ley 6/1994, cuya constitucionalidad no ha sido cuestionada por la recurrente, respecto a la actividad extractiva de recursos de la sección A) de la Ley de Minas constituye el ejercicio legítimo de la potestad legislativa de la Comunidad Autónoma de Madrid para delimitar y proteger los espacios naturales, de conformidad con la función social de la propiedad, por lo que no existe responsabilidad patrimonial y no procede la indemnización. Por ello, declara no haber lugar al recurso de casación. Destacamos el siguiente fundamento jurídico:

La Ley 6/1994, de la Comunidad de Madrid, respecto a la que no se invoca infracción alguna en los motivos de casación planteados y cuya inconstitucionalidad, como ya hemos señalado, no se suscita por la recurrente, ha sido aplicada por la sentencia de instancia sin contradecir ni vulnerar las normas en las que se sustenta el motivo de casación en estudio, art. 1 del Protocolo 1 del CEDH, así como el art. 33.3 y 106.2 de la CE y art. 139.1 de la LRJAPyPAC.

$[\ldots]$

[L]a medida de prohibición de la actividad de extracción de áridos, cuya efectividad ya prevé la disposición adicional cuarta de La Ley 6/1994, forma parte de la configuración legal de las facultades del dominio y los derechos existentes sobre dichos terrenos establecida por la ley autonómica, y no supone en sí misma privación de propiedad alguna, ni de bienes y derechos patrimoniales, sino tan sólo el establecimiento de las limitaciones generales y específicas que respecto de los usos y actividades han de establecerse como medidas necesarias para la conservación de los espacios naturales a proteger, todo ello en aplicación de la previsión del propio art. 33.2 de la CE que proclama que "[1]a función social de estos derechos delimitará su contenido, de acuerdo con las leyes", así como del segundo párrafo del art. 1 del Protocolo 1 del CEDH que reconoce el derecho de los Estados "de poner en vigor las Leyes que juzguen necesarias para la reglamentación del uso de los bienes de acuerdo con el interés general". 
La conformidad de este tipo de medidas legales con la configuración constitucional del derecho de propiedad ha sido declarada por el Tribunal Constitucional reiteradamente, y así en su sentencia 170/1989, de 19 de octubre (FJ 8) señala que "el límite entre la privación de un derecho patrimonial y su simple incidencia o delimitación legal amparándose en la función social a la que debe sujetarse (art. 33.2 de la Constitución) no es siempre fácil de determinar. En este sentido, y a partir de la doctrina general sobre el contenido esencial de los derechos constitucionales, se ha señalado respecto del derecho de propiedad que 'la fijación de su contenido esencial no puede hacerse desde la exclusiva consideración subjetiva del derecho de los intereses individuales que a éste subyacen, sino que debe incluir igualmente la necesaria referencia a la función social, entendida no como mero límite externo a su definición o a su ejercicio, sino como parte integrante del derecho mismo' - STC 37/1987- Partiendo de este dato y de las previsiones de otros preceptos constitucionales (arts. 128.1, 40, 45 y 130, entre otros), los poderes públicos deben 'delimitar el contenido del derecho de propiedad en relación con cada tipo de bienes'. Esto no supone, claro está, una absoluta libertad del poder público que llegue 'a anular la utilidad meramente individual del derecho', o, lo que es lo mismo, el límite se encontrará, a efectos de la aplicación del art. 33.3 C.E., en el contenido esencial, en no sobrepasar las barreras más allá de las cuales el derecho dominical y las facultades de disponibilidad que supone resulte reconocible en cada momento histórico y en la posibilidad efectiva de realizar el derecho".

En el presente supuesto, la prohibición introducida por la Ley 6/1994 de la Comunidad de Madrid respecto a la actividad extractiva de áridos, grava y arena en cuestión (recursos de la Sección A de la Ley de Minas), constituye el ejercicio legítimo de la potestad legislativa de la Comunidad Autónoma para la delimitación y protección de los espacios naturales objeto de la ley, de conformidad con la función social de la propiedad, tal y como autoriza el art. 33.2 de la CE. La ausencia de previsión explícita en la ley autonómica de indemnización alguna por razón de la prohibición que ha afectado a la recurrente es clara, atendido el tenor del art. 7 de la citada Ley 6/1994, que la limita expresamente a los aprovechamientos agrarios, sin que la recurrente haya sostenido la inconstitucionalidad de la ley. Pero tampoco resulta posible la interpretación que pretende la recurrente, de que la previsión de indemnización admitida por la propia Ley cuando se refiere a aprovechamientos agrarios, pueda entenderse implícitamente ampliada a las prohibiciones y límites a los aprovechamientos mineros, como consecuencia directa de los art. 33.3 y 106.2 de la $\mathrm{CE}$ y art. 1 del Protocolo $1 \mathrm{de} \mathrm{CEDH}$, que son los preceptos que invoca como infringidos [...]. La no previsión de indemnización alguna por límites al contenido 
de la propiedad que se han introducido por el legislador, precisamente en atención a la función social de la propiedad de los bienes incluidos en el espacio natural protegido en la Ley 6/1994, es conforme a los límites constitucionales y no desconoce el contenido esencial del derecho de propiedad y en modo alguno se puede equiparar el aprovechamiento de recursos mineros de la Sección A con el uso tradicional y consolidado de los terrenos rústicos, dada la naturaleza de la actividad extractiva y su subordinación a un régimen de autorización como el previsto en la Ley 22/1973, de 21 de julio, de Minas. Por tanto la sentencia recurrida no vulnera ni el citado art. 33.3 de la CE, como tampoco el art. 1 del Protocolo 1 del CEDH, cuyo contenido no se opone a la interpretación que de la Ley 6/1994 de la Comunidad de Madrid hace la sentencia recurrida.

$[\ldots]$

Por último, no se puede apreciar lesión alguna del art. 106.2 de la CE [...], como tampoco del art. 139.1 de la LRJAPyPAC que reproduce el mandato constitucional del art. 106.2 CE, pues excluyendo la propia Ley 6/1994 la indemnización por razón de las prohibiciones establecidas, y siendo estas prohibiciones y limitaciones conformes con la configuración constitucional de derecho de propiedad, en tanto que imponen límites en atención a la función social de los bienes afectados, no existe sino una determinación legal del contenido normal del derecho de propiedad y de la autorización de explotación que le fue otorgada, que la recurrente tiene el deber jurídico de soportar [FJ 5..].

Sobre una cuestión similar resuelve la STS de 19 de septiembre de 2016 (ponente: César Tolosa Tribiño) ${ }^{8}$, puesto que tiene relación con espacios naturales protegidos y actividades extractivas. En esta ocasión son la Generalitat de Catalunya y la Diputació de Barcelona quienes interponen recurso de casación contra la Sentencia de 26 de marzo de

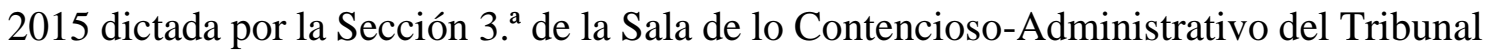
Superior de Justicia de Cataluña. Esta sentencia estimó el recurso interpuesto por Mármoles y Triturados Deulofeu, S. A., contra la Resolución del Consejero de Política Territorial y Obras Públicas, de 11 de diciembre de 2008, de aprobación definitiva del Plan Especial de Protección del Medio Natural y del Paisaje del Parque Natural del Montseny, y declaró la nulidad del artículo 96 del citado Plan (este precepto no permite la implantación de nuevas actividades extractivas, excepto que se obtenga la correspondiente autorización de forma motivada, por concurrir las circunstancias

\footnotetext{
${ }^{8}$ ROJ: STS 4064/2016 - ECLI:ES:TS:2016:4064.
} 
previstas en el propio precepto), sin efectuar especial pronunciamiento impositivo de las costas procesales. La cuestión de fondo que se plantea es la conformidad con el ordenamiento jurídico del establecimiento de prohibiciones de actividades extractivas en espacios naturales protegidos $\mathrm{y}$, en particular, la legalidad de un instrumento de planificación de un espacio natural protegido que contiene una prohibición de actividades extractivas. En este caso, el Tribunal Supremo se pronuncia a favor de la legalidad del Plan Especial objeto de controversia. En consecuencia, estima el recurso interpuesto y declara la legalidad del artículo 96 del Plan Especial de Protección del Medio Natural y del Paisaje del Parque Natural del Montseny, y, por lo tanto, de la totalidad de este, al considerar que no se incluye una prohibición genérica de actividades extractivas. El Plan exige motivar las razones de la autorización para que puedan autorizarse nuevas explotaciones mineras, pero eso no supone una prohibición genérica, por lo que no es contrario a derecho.

Es interesante destacar las partes en las que la Sentencia repasa los principales pronunciamientos jurisprudenciales del TC y del TS sobre la materia:

Sobre la cuestión de fondo que se plantea en ambos recursos, la STC 64/1982 concedió prevalencia al art. 128.1 CE, considerando contrario a lo dispuesto en el mismo y en el art. $45 \mathrm{CE}$, la prohibición genérica de las actividades extractivas, por sustraerse de la riqueza nacional los recursos mineros, admitiendo que las Comunidades Autónomas impongan cargas adicionales para proteger el medio ambiente, pero no la prohibición general de las actividades extractivas de las secciones C) y D), que son las de mayor importancia económica. Esta doctrina fue aplicada en la STC 170/1989, que desestimó el recurso, precisamente, porque la prohibición quedaba limitada a unos terrenos muy concretos, y destinada, fundamentalmente, a las secciones A) y B), y se entendió que estaba implícito un interés público prioritario.

Por otra parte, existe ya una doctrina consolidada caracterizada por:

1. Estimar la ilegalidad de aquellos instrumentos de planificación prohibitivos de actividades extractivas que no estaban correctamente justificados.

Es el caso de la STS de 23 de marzo de 2012, RC 2650 / 2008, así como las que en ella se citan, por la que fue confirmada la anulación del artículo 24 del Plan Especial Municipal de Protección del Paraje Natural "La Dehesa", en el término municipal de Soneja (Castellón), que prohibía las actividades extractivas porque "La prohibición de la actividad extractiva, contenida en el artículo 24 del plan especial, no se justifica, porque en la memoria del plan figura que la 'minería es inexistente 
en la actualidad en el ámbito del plan'. [...] No está de más añadir que sobre la falta de justificación de este tipo de prohibiciones, contenidas en el planeamiento, nos hemos pronunciado recientemente, aunque en casos no exactamente asimilables al ahora enjuiciado, en Sentencias de 30 de noviembre de 2011 (recurso de casación n. ${ }^{\circ} 5617 / 2008$ ) y de 3 de noviembre de 2010 (recurso de casación n. ${ }^{\circ}$ 5294/2007 )". En el mismo sentido, en la STS de 14 de febrero de 2012, RC 1049/2008, fue declarada ajusta[da] a derecho la prohibición por el Plan General de Ordenación Urbana de Actividades Extractivas Mineras en el término municipal de Vilafamés, por cuanto tal prohibición se llevó a cabo tras un exhaustivo juicio de ponderación, en el que se consideró prevalente la protección ambiental.

2. Ilegalidad de las prohibiciones extractivas previstas con carácter de generalidad. Es el caso de la STS de 30 noviembre de 2011, RC 5617/2008, por la que fue confirmada la anulación por la Sala de instancia de una Modificación Puntual de Normas Subsidiarias de Las Navas del Marqués (Ávila), que tenía por objeto prohibir en el suelo rústico común las actividades extractivas, por considerar que tal prohibición genérica no estaba justificada o amparada en informe alguno. También debemos citar la STS de 3 de noviembre de 2010, RC 5294/2007, en que fue anulada la prohibición total de extracciones mineras en determinados suelos de Segovia y su Entorno, contenida en las Directrices de Ordenación Subregional, y la STS de 18 de octubre de 2012, RC 5917/2009, en que declaramos que “[...] En cualquier caso, lo que aquí interesa destacar es que los instrumentos de ordenación urbanística pueden establecer limitaciones o hasta prohibiciones a las actividades mineras y así lo hemos recordado en nuestra sentencia de 3 de noviembre de 2010 (casación 5294/2007), respetando, en todo caso, que conforme a la doctrina del Tribunal Constitucional la prohibición genérica de las actividades extractivas y mineras en un extenso espacio a fin de proteger el medio ambiente requiere la ponderación de la importancia que para la economía nacional implica la explotación minera de que se trate y el daño que se pueda producir al medio ambiente (véase sentencia del Tribunal Constitucional 64/1982".

3. Legalidad en la denegación de autorización de actividades extractivas por estar los suelos clasificados como no urbanizables protegidos. Es el caso de la STS de 1 de junio de 1998, Recurso de Apelación 6492/1992, en la que fue confirmada la denegación de actividad extractiva por estar el suelo clasificado como no urbanizable protegido; sentencia en la que se indicaba que con tal protección “... de suyo va que habrán de estar prohibidas todas aquellas actividades que, como las extractivas, (que destruyen la propia configuración del suelo), alteran éste en mucho mayor grado que las edificaciones unifamiliares o las granjas, prohibidas, sin embargo, expresamente. 
Una interpretación de esa norma que tenga en cuenta su contexto, su espíritu y la realidad social (artículo $3 .^{\circ}-1$ del Código Civil), no puede ser otra, pues de admitirse estas actividades en tal lugar podría llegarse a la pura y simple desaparición de las características de un suelo que se quería proteger, lo que sería un completo sin sentido [...] [FJ 10. ${ }^{\circ}$.

Conforme a la sentencia 235/2015, de 5 de noviembre de 2015 (BOE núm. 296, de 11 de diciembre de 2015), del Tribunal Constitucional, dictada en relación con el art. 47 de la Ley 13/2005, de 27 de diciembre, de medidas tributarias y administrativas de la Comunidad Autónoma de Illes Balears: 'No hay duda alguna acerca de la necesidad de adoptar las medidas necesarias para garantizar que el ejercicio de los derechos mineros se realice sin menoscabo del medio ambiente y en condiciones tales que no produzca un grave detrimento de los terrenos afectados'. En ese sentido, la STC 106/2014, FJ 8 a), recuerda que 'De la doctrina constitucional se infiere sin dificultad que, con la finalidad de protección del medio ambiente, la Comunidad Autónoma puede imponer requisitos y cargas para el otorgamiento de autorizaciones y concesiones no previstos por la legislación estatal, pero sin alterar el ordenamiento básico en materia de régimen minero y energético', que es lo que ha sucedido en el presente caso" [FJ 13. ${ }^{\circ}$.

El Tribunal Supremo también resuelve en este período sobre protección del paisaje en relación con el urbanismo. La STS de 29 de junio de 2016 (ponente: Francisco José Navarro Sanchís) ${ }^{9}$ resuelve un recurso de casación que confirma la sentencia de instancia del TSJ de Galicia en la que se declara la nulidad de un plan parcial por incumplir los criterios paisajísticos señalados en la memoria ambiental. Además, el Alto Tribunal considera que se tendría que haber recogido la alegación planteada por la asociación recurrente sobre la incorrecta clasificación de este sector como suelo urbanizable:

En suma, la razón de decidir apreciable en la sentencia ahora recurrida es que el Ayuntamiento de Sanjenjo aceptó, en tanto que en lo relativo al impacto visual, por razón de la distribución de las viviendas en hileras continuas y la falta de fragmentación del volumen edificado, se prescindió por completo de la terminante objeción, de un valor significativo en tanto el órgano ambiental pone de relieve el valor medioambiental de la zona, debido en buena medida a su interés forestal, fuente a su vez del paisajístico, la reacción municipal es, como indica la sentencia, puramente negativa, esto es, de mera desatención a lo ordenado.

\footnotetext{
${ }^{9}$ ROJ: STS 3367/2016; ECLI:ES:TS:2016:3367.
} 
Habría sido más completo el análisis jurídico del asunto si la sentencia hubiera tomado en consideración — para atenderla — la alegación de la demanda relativa a la incorrecta clasificación como suelo urbanizable del espacio delimitado como SU14 en el Plan General, que se rechaza preliminarmente sobre la base de una rigorista concepción del recurso indirecto frente a disposiciones generales, aquí trasladable a las relaciones entre instrumentos de planeamiento, pero tal limitación no es posible superarla en casación ante una sentencia estimatoria que sólo acoge un motivo, pero determinante a su vez de la invalidez de todo el plan parcial objeto de la impugnación. Pues bien, no es aceptable que corresponda al órgano promotor, en la terminología de la Ley 9/2006, esto es, al Ayuntamiento que adopta la iniciativa de aprobación del plan parcial sometido a evaluación ambiental estratégica, calificar sus propias soluciones ambientales -movidas obviamente por el lógico deseo de mantenimiento a todo trance del plan parcial sometido a evaluación - como mejores que las ofrecidas en la Memoria ambiental o suficientes para enervar el efecto adverso de un informe desfavorable, fuera o no vinculante en un sentido estricto.

El Alto Tribunal también ha dictado sentencia en materia de desarrollo urbanístico sostenible, la STS de 1 de junio de 2016 (ponente: Francisco José Navarro Sanchís) ${ }^{10}$. En ella se invoca este principio para fundamentar la consideración de que las previsiones del Plan General de Ordenación Urbana en cuestión — que preveía la creación de una nueva zona industrial de grandes dimensiones - atentan contra dicho principio, cuyo fin es apostar por un nuevo modelo de ciudad que exige que la reclasificación de suelo urbanizable nuevo esté basada en unas necesidades reales que lo justifiquen. En este caso, además de no existir dichas necesidades, se reclasificaba en parte suelo forestal protegido.

Destacamos a continuación la STS de 19 de septiembre de 2016 (ponente: César Tolosa Tribiño) ${ }^{11}$, que resuelve un recurso de casación relacionado con la gestión de residuos. En concreto, trata sobre los planes autonómicos de gestión de residuos y sobre la autonomía local de los municipios en materia de ordenación, gestión, ejecución y disciplina urbanística. En particular, el ayuntamiento recurrente critica la imposición de un modelo de ciudad en cuanto a la ubicación de plantas de tratamiento de residuos. Se plantea, en definitiva, la coordinación de las competencias municipales y autonómicas con motivo de la aprobación de un plan autonómico de gestión de residuos y, en

\footnotetext{
${ }^{10}$ STS 2480/2016 - ECLI:ES:TS:2016:2480.

${ }^{11}$ ROJ: STS 4067/2016 - ECLI:ES:TS:2016:4067.
} 
particular, el alcance de las competencias municipales y autonómicas en este ámbito. El Tribunal Supremo desestima el recurso de casación presentado por el Ayuntamiento de Cox y le impone las costas procesales al no apreciar razones que justifiquen no hacerlo, señalando como cifra máxima la de 4.000,00 euros más IVA por cada uno de los personados para oponerse al recurso. Veamos en qué se fundamenta:

El Tribunal Constitucional ha señalado de forma reiterada que la garantía institucional de la autonomía local reconocida en los artículos 137 y 140 de la Constitución tiene un contenido mínimo que el legislador debe respetar y que se concreta, básicamente, en el “... derecho de la comunidad local a participar a través de órganos propios en el gobierno y administración de cuantos asuntos le atañen, graduándose la intensidad de esta participación en función de la relación existente entre los intereses locales y supralocales dentro de tales asuntos o materias" (STC 240/2006, de 20 de julio, que recoge lo declarado en las anteriores SsTC 32/1981 y 40/1998). Se trata, por tanto, de una noción muy similar a la acogida por la Carta Europea de la Autonomía Local de 1985, ratificada por España a través de Instrumento de ratificación de 20 de enero de 1988, depositado el 8 de noviembre de 1988, y entrada en vigor para España el 1 de marzo de 1989.

A salvo ese contenido mínimo de la autonomía local, estamos ante "un concepto jurídico de contenido legal" que se concreta en una garantía institucional de los elementos primarios o fundamentales, es decir, del núcleo esencial del autogobierno de los entes públicos territoriales de ámbito local, que debe necesariamente ser respetado por el legislador para que dichas Administraciones sean reconocibles como entes dotados de autogobierno. Respeto igualmente exigibles a las demás Administraciones en la aplicación de las leyes y en las relaciones con los entes locales, de conformidad con la interpretación realizada por la doctrina del Tribunal Constitucional.

La expresada autonomía local se proyecta sobre intereses locales y competencias municipales, siendo indiscutiblemente el urbanismo un asunto de interés de los municipios y sobre el cual, por tanto, extienden éstos sus competencias, como señala la STC $240 / 2006$ recordando lo declarado en la STC 40/1998. Ahora bien, en este ámbito confluyen intereses de diferente naturaleza y, por lo que aquí importa, de distinta intensidad y ámbito territorial, de suerte que únicamente cuando dichos intereses públicos concernidos rebasan el ámbito puramente local se legitima el control por parte de otras administraciones [ $\left.\mathrm{FJ} 8^{\circ}{ }^{\circ}\right]$.

[...] el Decreto impugnado, en ningún caso invade competencias municipales ni en materia urbanística ni en materia de residuos, sino que dicho instrumento de 
planeamiento se elabora partiendo del principio general de coordinación de competencias entre la Generalitat y las Administraciones locales Valencianas en orden a lograr una planificación concertada y eficaz en materia de residuos.

En definitiva, se llama a la coordinación adecuada entre las diferentes administraciones implicadas y sus intereses. En concreto, el Tribunal Supremo afirma la competencia autonómica en materia de ordenación del territorio y urbanismo, que legitima la aprobación de planes de ámbito superior al territorio municipal, pero también exige el cumplimiento de tres requisitos fundamentales que actúan como límite frente a la planificación supramunicipal y que deben permitir que los intereses municipales queden a salvo, a saber: la participación efectiva de los municipios en los planes que les afecten; la garantía material del interés local en la ordenación del territorio municipal, por lo que el plan debe circunscribirse a los aspectos supramunicipales; y el principio de proporcionalidad.

En este período el Alto Tribunal también ha tratado cuestiones relacionadas con la asignación de derechos de emisión. En la STS de 18 de mayo de 2016 (ponente: César Tolosa Tribiño) ${ }^{12}$ la recurrente considera que la cantidad de derechos asignados para el período 2013-2020 tendría que haber sido mayor, ya que no se han tenido en cuenta ni la circunstancia de riesgo de fuga ni el método de cálculo llevado a cabo por la empresa en cuanto a la capacidad inicial instalada. El Tribunal desestima la pretensión. Esta sentencia muestra la complejidad a la hora de determinar dichos derechos y aplicar el procedimiento y las guías para otorgarlos.

Finalmente, debemos tratar las distintas sentencias que encontramos en este período relativas a energías renovables, especialmente sobre su régimen retributivo. Todas analizan el Real Decreto 413/2014, de 6 de junio, por el que se regula la actividad de producción de energía eléctrica a partir de fuentes de energía renovables, cogeneración y residuos, contra la aprobación del cual se interponen distintos recursos ${ }^{13}$.

La STS de 1 de junio de 2016 (ponente: Pedro José Yagüe Gil) ${ }^{14}$ plantea una cuestión prejudicial ante el TJUE en relación con la interpretación de la Directiva 2009/28/CE, de

\footnotetext{
${ }^{12}$ ROJ: STS 2330/2016 - ECLI: ES:TS: 2016:2330.

${ }^{13}$ Además de las comentadas sobre esta materia, también encontramos las sentencias con las siguientes referencias: ROJ: STS 3596/2016; STS 3798/2016; STS 4114/2016.

${ }^{14}$ ROJ: STS 2427/2016 - ECLI: ES:TS: 2016:2427.
} 
energías renovables, y una cuestión de inconstitucionalidad ante el TC del Real Decreto Ley 9/2013, de 12 de julio, por el que se adoptan medidas urgentes para garantizar la estabilidad financiera del sistema eléctrico, la Ley 24/2013, de 26 de diciembre, del Sector Eléctrico, y el Real Decreto 413/2014 por vulneración de los artículos 86.4 y 9.3 CE, además de la nulidad del Real Decreto 413/2014 o, en su defecto, la nulidad de su artículo 13.3. El Alto Tribunal desestima el recurso. Para ello se basa en las SSTC 270/2015, 19/2016, 29/2016, 30/2016 y 61/2016, y descarta la vulneración de los principios de irretroactividad, seguridad jurídica y confianza legítima. Considera que se ha dado participación al público de forma correcta y que el Real Decreto 413/2014 es compatible con la Directiva invocada y con los objetivos de fomento de dichas energías.

La STS de 7 de junio de 2016 (ponente: José Manuel Bandrés Sánchez-Cruzat) ${ }^{15}$ destaca por ser una sentencia compleja que trata sobre la regulación de las energías renovables y el modelo adoptado por el Estado español. Esta sentencia resuelve el recurso contenciosoadministrativo contra el Real Decreto 413/2014 y contra la Orden del Ministerio de Industria, Energía y Turismo IET/1045/2014, de 16 de junio, por la que se aprueban los parámetros retributivos de las instalaciones tipo aplicables a determinadas instalaciones de producción de energía eléctrica a partir de fuentes de energía renovables, cogeneración y residuos. En esta ocasión se pide la nulidad de varios artículos del Real Decreto por entenderlos contrarios a derecho por desviación de poder y con efectos retroactivos lesivos para la mercantil recurrente. En el caso de que se estime el recurso, pide una compensación económica por daños. El recurso se basa, entre otros argumentos, en la incompatibilidad con la Ley 24/2013, de 26 de diciembre, del Sector Eléctrico. Sin embargo, el Alto Tribunal desestima el recurso sobre la base de la STC 270/2015 y la abundante jurisprudencia del propio Tribunal sobre la interpretación y el alcance de cada uno de los principios que señala el recurso. Estos son, de nuevo, el principio de irretroactividad, el principio de confianza legítima, el principio de proporcionalidad y el principio de estabilidad regulatoria. No obstante, se emiten dos votos particulares de los magistrados Eduardo Espín Templado - que considera que sí que hay retroactividad contraria a derecho por vulnerar los principios de seguridad jurídica y confianza legítima y que hubiera procedido la estimación parcial del recurso- - y Eduardo Calvo Rojas, al que se adhiere una tercera magistrada, María Isabel Perelló Domènech — quien cuestiona también la solución dada al principio de irretroactividad al apreciar una irretroactividad

${ }^{15}$ ROJ: STS 2689/2016 - ECLI: ES: TS: 2016:2689. 
ilícita por contravención de los principios de seguridad jurídica y confianza legítima, y discrepa en relación con la Orden impugnada-.

La STS de 10 de junio de 2016 (ponente: Pedro José Yagüe Gil) ${ }^{16}$ resuelve un recurso contencioso-administrativo interpuesto por una mercantil en el que se pide la anulación completa del Real Decreto 413/2014 o, en su defecto, de su disposición final segunda. El Tribunal desestima el recurso y mantiene su postura ya expuesta en otras sentencias anteriores. Considera que estamos ante una fórmula de fomento de las energías renovables.

La STS de 24 de junio de 2016 (ponente: Diego Córdoba Castroverde) ${ }^{17}$ y la STS de 28 de junio de $2016^{18}$ reiteran parcialmente los pronunciamientos de la STS de 7 de junio de 2016 y de la STS de 10 de junio de 2016 ya mencionadas. En esta ocasión, a pesar de que desestima de nuevo las pretensiones planteadas, el Tribunal estima la nulidad del artículo 49.1.m del Real Decreto impugnado por entender que es contrario al principio de proporcionalidad en relación con la amplitud con la que describe la conducta que conlleva la cancelación de la inscripción y la consiguiente pérdida de retribución. Cabe señalar que esta sentencia también tiene dos votos particulares, similares a los planteados en la STS de 7 de junio:

Esta Sala considera que, en los términos tan laxos en que aparece redactada la disposición reglamentaria impugnada, que no contiene ninguna especificación precisa acerca de la entidad, la naturaleza o la relevancia del incumplimiento de las obligaciones y requisitos exigidos a los titulares de instalaciones de generación de electricidad a partir de fuentes de energía renovables para acogerse al régimen retributivo específico, que comporta en el supuesto de que se haya acreditado dicho incumplimiento la cancelación de la inscripción en el registro de dicho régimen retributivo específico, y, en consecuencia, la pérdida de la retribución, el Gobierno, en el ejercicio de su potestad reglamentaria, ha vulnerado el principio de proporcionalidad.

En efecto, cabe poner de relieve que el principio de proporcionalidad impone, según una consolidada jurisprudencia del Tribunal de Justicia de la Unión Europea, del Tribunal Constitucional y de esta Sala de lo Contencioso-Administrativo del

\footnotetext{
${ }^{16}$ ROJ: STS 2692/2016 - ECLI: ES:TS: 2016:2692.

${ }^{17}$ ROJ: STS 3079/2016 - ECLI: ES:TS: 2016:3079.

${ }^{18}$ ROJ: 3088/2016.
} 
Tribunal Supremo, que en la predeterminación de aquellas normas cuya aplicación comporte efectos perjudiciales para los afectados, debe tenerse en cuenta que la regulación adoptada sea adecuada y necesaria para garantizar los fines u objetivos de interés general perseguidos por la norma habilitante, sin que, por tanto, puedan introducirse disposiciones que por su carácter se revelen extremadamente o injustificadamente gravosas.

En este sentido, estimamos que no cabe aceptar, desde la perspectiva de respeto debido al principio de seguridad jurídica, - aunque no esté en juego en este supuesto la aplicación del principio de tipicidad garantizado en el artículo 25 de la Constitución ni las garantías contenidas en los artículos 129 y siguientes de la Ley 30/1992, de 26 de noviembre, de Régimen Jurídico de las Administraciones Públicas y del Procedimiento Administrativo Común, por no tener la disposición enjuiciada carácter sancionador-, aquellas cláusulas reglamentarias que comporten un halo de incertidumbre por no precisar los elementos objetivos constitutivos del presupuesto de la conducta antijurídica, como es, en este caso, la relevancia o gravedad del incumplimiento, que no permite a los destinatarios de la norma poder conocer y predecir, sin ambigüedad, las consecuencias derivadas de su actuación [FJ 8. ${ }^{\circ}$.

La STS de 26 de julio de 2016 (ponente: Eduardo Espín Templado) ${ }^{19}$ resuelve un recurso contencioso-administrativo también contra el Real Decreto 413/2014 y contra la Orden IET/1045/2014, de 16 de junio, por la que se aprueban los parámetros retributivos de las instalaciones tipo aplicables a determinadas instalaciones de producción de energía eléctrica a partir de fuentes de energía renovables, cogeneración y residuos. Se plantea el tratamiento equivocado de las empresas de cogeneración de residuos de purines, ya que se incluyen como empresas de cogeneración ordinarias. El Tribunal Supremo estima el recurso y anula la Orden impugnada, ya que entiende que este tipo de instalaciones de cogeneración tienen una regulación específica (Real Decreto Ley 9/2013) que la Orden ha ignorado. Por ello, además de anular la Orden en cuestión, ordena a la Administración general del Estado que en el plazo de cuatro meses apruebe la regulación sustantiva que anula. Destacamos los siguientes párrafos:

La Orden IET/1045/2014 ha ignorado las singularidades de las plantas de tratamientos de purines, que desde su origen han venido siendo consideradas como instalaciones de producción de energía eléctrica distintas a las de cogeneración y estrechamente vinculadas al compromiso medioambiental de tratamiento y

\footnotetext{
${ }^{19}$ ROJ: STS 3797/2016 - ECLI: ES: TS: 2016:3797.
} 
reducción de residuos; consideración ésta que se mantiene en el Real Decreto 413/2014 (disposición adicional segunda, apartado 8), que continúa exigiendo el tratamiento del purín como condición para la percepción de la retribución específica. El hecho de que todas las instalaciones de tratamiento de purines existentes en España hayan cesado en su actividad no es por sí mismo una prueba determinante; pero tiene un indudable valor indicativo de las disfunciones que han generado los parámetros establecidos en la Orden IET/1045/2014 [FJ 2. ${ }^{\circ}$ in fine].

En este período el Alto Tribunal también ha dictado sentencias en materia de aguas ${ }^{20}$, telecomunicaciones ${ }^{21}$ y subvenciones relacionadas con el medio ambiente ${ }^{22}$, entre otras.

\footnotetext{
${ }^{20}$ ROJ: STS 3659/2016; STS 3672/2016.

${ }^{21}$ ROJ: STS 3762/2016.

${ }^{22}$ ROJ: STS 3759/2016.
} 